\title{
Effect of Body Positioning Intervention Program on Relieving Gastroesophageal Reflux Disease in Preterm Infants
}

\author{
Samah M. Khalaf ${ }^{l} \&$ Faten S. Mahmoud $^{2}$ \\ ${ }^{1}$ Lecturer of Pediatric Nursing, ${ }^{2}$ Assistant Professor of Pediatric Nursing
}

\begin{abstract}
Gastroesophageal reflux Disease (GERD) is a very common problem among preterm infants, it is a challenging clinical entity that has often been associated with a number of negative clinical outcomes. The purpose of the study was to evaluate the effect of body positioning intervention program on relieving Gastroesophageal Reflux disease in preterm infants. The design of this study was a quasi - experimental research design. This study was carried out at Neonatal Intensive Care Units in Benha specialized hospital for children. A convenient sample of 60 nurses working at the study setting and a purposive sample of 60 neonates who suffering from Gastroesophageal reflux (GERD). Three instruments were utilized to collect data for this study; A structured interviewing questionnaire sheet, Observational assessment checklists and Pain assessment scales. The results of this study revealed that, nursing intervention in the form of body positioning guidelines improved medical outcomes of preterm infants with Gastroesophageal reflux disease on post program phase compared with preprogram phase. The study concluded that, preterm infants who exposed to the intervention program in the form of body positioning had better mean scores in relation to their medical outcomes post program compared with preprogram intervention. Therefore it is recommended that, intervention program in the form of body positioning should be applied to help in relieving Gastroesophageal reflux disease in preterm infants
\end{abstract}

Key words: Body Positioning, Intervention Program, Gastroesophageal Reflux disease, Preterm Infants.

\section{Introduction:}

Gastroesophageal reflux (GOR) is the involuntary retrograde passage of gastric contents into the esophagus with or without regurgitation or vomiting. As, it is a frequently experienced physiologic condition occurring several times during the day, mostly postprandial and causes no symptoms. It considered a developmental condition of young infants and older adults (Steven \&Blanchard, 2013).

Preterm infants are very liable to Gastroesophageal reflux. Those neonates are also called 'happy spitters'. As, in those neonates the reflux of stomach contents spit up into the mouth. In many cases it is quite common and usually not accompanied by any evidence of distress. But GOR of this degree typically decreases with age and is uncommon by about 10 months of age. On the other hand, if reflux into the esophagus or mouth is accompanied by distress, the infant may be said to have gastroesophageal reflux disease (GERD) (Vandenplas et al.,2009).So, if the muscle opens too frequently and refluxing occurs too often, complications can develop. So, reflux episodes sometimes trigger vomiting, a coordinated autonomic and voluntary motor response, causing forceful expulsion of gastric contents through the mouth. Vomiting associated with reflux is probably a result of the stimulation of pharyngeal sensory afferents by refluxed gastric contents (Sudarshan et al., 2013).

Generally, it affects the quality of life and can cause pathologic complications such as; failure to thrive, feeding or sleeping problems, chronic respiratory disorders, esophagitis, hematemesis, apnea, and apparent life-threatening events. Rathermore, symptoms of GERD include: regurgitation, irritability, excessive crying, disturbed sleep, impaired feeding tolerance, poor weight gain and respiratory complications. GERD that is more than minimally symptomatic may require more extensive diagnosis and treatment(Lightdale \& Gremse,2013).

Symptomatic reflux called gastroesophageal reflux disease (GERD) affects infants and causes a variety of symptoms and observable events. The diagnosis of GER or it appears to be increasing in the infant population including full term and preterm newborns who hospitalized for a variety of reasons. Much evidence suggests that, the incidence of GERD decreases with increasing gestational age. These treatments are not without risks and side effects. While some 
treatments are as benign as elevating the head of an infant's bed to prevent reflux, others include medications that have been shown to increase the risk of other illnesses including acute gastro enteritis and pneumonia (Sangers et al.,2013).

The long-term risk of GERD in premature infants during adulthood is controversial. Whereas, it may lead to long-term complications, such as; lung aspiration, esophagitis, feeding problems, inadequate weight gain, narrowing of the esophagus, damage to the esophageal tissues (called Barrett's syndrome) and failure to thrive (Maroney,2015).

The pathogenesis of GERD in preterm infants appears to be multifactorial due to immature or impaired anatomic and physiologic factors that typically limit reflux. The most important mechanism of GERD in preterm infants is similar to older infants and adults. As it is a transient relaxation of the lower esophageal sphincter (LES). The LES is comprised of intrinsic smooth muscle of the esophagus and skeletal muscle of the diaphragm (Martin, 2016).

A worldwide incidence of prematurity in 2010 was 11.1 per 100 live births. But there was a significant variation in rates by country and region of the world was noted, but this variation is smaller than observed for a number of other important reproductive outcomes. Rathermore, prematurity related complications were arisen, as it may affect neonates and have many risks to life. The highest rates of preterm birth were in Africa and North America (11.9\% and $10.6 \%$ of all births, respectively) (Nestle Nutrition Institute work shop Series, 2015). In Egypt, it was estimated that, the Extrapolated incidence of premature birth was 123,131 in 2016 (The Right Diagnosis,2016). Globally, one in 10 of these premature NICU infants were diagnosed with GERD, which is associated with substantially increased length of hospital stay (LOS) and elevated costs. Better diagnostic and management strategies are needed to evaluate reflux-type symptoms in this vulnerable NICU population (Sangers et al.,2013).

Gastroesophageal reflux (GOR) is one of the most common related problems to prematurity in neonates that causes morbidity. Whereas, putative morbidities of GOR in preterm infants include; frequent vomiting, aspiration pneumonia, irritability, failure to thrive, and exacerbation of respiratory symptoms, including chronic lung disease. However, it is likely that in many infants with these symptoms, the GER is not the underlying cause (Sudarshan et al., 2013).

The nursing staff in the Neonatal Intensive Care Unit (NICU), commonly reported GERD based on observable behaviors of neonates including; arching, irritability, desaturations, apnea, and bradycardia(Chairs et al.,2009). Therapeutic management of GERD still represents a controversial issue among neonatal care providers. A stepwise approach, promoting at first non pharmacological interventions such as; body positioning, milk thickening, or modifications in feeding modalities, should be considered (Hammell, 2009). Globally, in recent years, the therapeutic management of GERD still represents a controversial issue among neonatal health care providers. A step wise approach, promoting at first non pharmacological interventions such as body positioning, which considered one of the most advisable choices to manage GOR in preterm infants. That, body positioning could help pharmacological treatment, which could be limited to those infants who do not benefit from conservative measures or who experience GOR clinical complications (Corvaglia et al., 2007).

\section{Significance of the study:}

Premature infants have an increased risk of developing GERD. There are several medical conditions that can cause reflux, but in premature infants, the most common causes are; immature muscles and abnormal breathing from chronic lung disease. As, if the lower esophageal sphincter is weak or underdeveloped, it may remain opened when it should be closed, that letting the stomach contents flow back up the esophagus. When an infant breathes abnormally because of chronic lung disease, the muscles used for breathing work harder. As these muscles work hard to breathe, they can pull on the muscles near the top of the stomach, stretching the sphincter and causing it to remain opened (Martin, 2016).

\section{Purpose of the study:}

The purpose of this study was to evaluate the effect of body positioning intervention program on relieving Gastroesophageal Reflux Disease in preterm infants.

\section{Through the following objectives:}

1) Assess nurses' knowledge and practice regarding GERD in pre-term infants

2) Designing and implementing an intervention program based on nurses' actual needs assessment about the best nursing practice in relieving GERD.

3) Evaluating the effect of implemented intervention program on nurses' knowledge and practice towards care of preterm infants with GERD.

4) Evaluating the effect of implemented intervention program on medical outcomes of preterm infants with GERD.

Hypotheses: 
1) Nurses will adhere to the instructions related to positioning of preterm infants on post program phase than on pre program phase

2) Nurses will have higher level of knowledge about body positioning for preterm infants on post program phase than on preprogram phase

3) Preterm infants will have fewer gastroesophageal refluxes on post program phase than on preprogram phase.

4) The pre-term infants who will expose to the intervention program in the form of body positioning will have better medical outcomes than before applying the intervention program

\section{Operational definitions:}

1) Gastro esophageal Reflux disease (GERD): is the passage of the gastric contents into the esophagus, with regurgitation and vomiting. It may represent a pathological condition named gastroesophageal reflux disease (GERD), when it causes symptoms or complications that are associated with significant morbidity.

2) Preterm infant: For this study the preterm infant included neonates who ranged from 28 to 35 equal or less than gestational weeks

3) The body positioning intervention included placing the preterm infants on left lateral position for 30 minutes post prandial.

\section{Methods}

1. Research design: A quasi -experimental design was utilized for conduction of this study

2. Research Settings: This study was conducted in neonatal intensive care units affiliated to Benha Specialized Hospital for children in Benha City.

3. Sampling: Consisted of two groups of subjects were included in the study as the following:

Group (1): A purposive sample of 60 male and female neonates who were admitted to NICU from the beginning of January 2016 to the end of March 2016 suffering from Gastro-esophageal reflux disease, with the following inclusion criteria :

1) Preterm infants (<36 weeks gestation)

2) Low birth weight $(<2500$ grams $)$ infants.

3) With signs or symptoms suggestive of GERD.

4) Breast and formula fed neonates.

\section{Criteria of exclusion: -}

1) Newborns with serious chronic pathology.

2) Major congenital malformations (e.g. congenital heart diseases, gastrointestinal abnormalities, malformation syndromes).

3) Neonatal necrotizing enterocolitis (NEC).

4) Ongoing infections.

5) Neonates with severe clinical conditions which can hinder participation in this study (e.g. patent duct us arteriosus, intra-ventricular hemorrhage, and hemodynamic instability).

6) Administration of experimental medication treatment during the previous two weeks.

7) Neonates fed by an oro gastric or nasogastric tube,

Group (2): A convenient sample of 60 bedside male and female nurses who were working at the previously mentioned setting regardless their characteristics.

Body positioning intervention: left lateral position

Instruments: Three instruments were utilized for data collection:-

* Instrument I: It involved a Structured Interview questionnaire. It was developed by the researchers based on the scientific literatures (Sangers et al.,2013, Sangers et al.,2013 and Maroney,2015). It was prepared in Arabic language to assess the nurses' knowledge regarding GERD. Each nurse was interviewed individually for answering the knowledge questionnaire sheet. It comprised three main parts which are:

- Part 1: Personal characteristics of the studied nurses as; age, gender, qualifications, years of experience and attendance of training courses regarding neonatal care.

- Part 2: Nurses' knowledge about GERD, which consisted of multiple choice questions and close ended questions covering the questions related to definition, causes, signs and symptoms of the disease, risky signs complications, proper position post prandial and nursing management. The scoring system consisted of giving score (1) for the correct answer and (0) for the wrong answer.

The scoring system for total knowledge classified as follows:

- Satisfactory knowledge level: Equal to or more than $70 \%$ 
- Unsatisfactory knowledge level: Less than $70 \%$

- Part 3: Neonates' characteristic sheet: It was designed by the researchers to collect data about characteristics of neonates after a review of related literatures. It included; gestational age, current age at the study time, weight on admission, current weight at study time.

Instrument II: Observational assessment Checklists: it was designed by the researchers to assess nurses' actual care of preterm with GERD and to observe the improvement in neonates' condition and accompanied problem related to GERD before and after program implementation It included four parts as the following:

- Part 1: To assess actual nurses' practices regarding care of preterm neonates with GERD. Each nurse was observed during each procedure for three different times using nurses' observational check lists.

The scoring system for practice classified as follows:

- Competent practice level: Equal to or more than $80 \%$

- Incompetent practice level: Less than $80 \%$

- Part 2: GERD episodes assessment sheet: To assess the following criteria related to GERD such as; the number of episodes and duration of GERD in infants, number of minutes until clearance of any GOR episode over a 24-hour period, duration of longest GOR episode in minutes (within two hours postprandial over a 24 hour period, Vomiting episodes (total number over a 24-hour period)

- Part 3: Respiratory status assessment sheet: It included; respiratory affection related to GERD, aspiration episodes, oxygen saturation within two hours postprandial and number of apneas (over a 24-hour period).

- Part 4: Weight gain assessment sheet: It was used to assess weight gain along six days from the beginning of interventions

* Instrument III: Pain assessment scales to assess pain accompanied GERD episodes in preterm neonates before and after the interventions. It included two scales as the following:

1-Preterm Infant Pain Profile(PIPP): It was adopted from (Stevens et al., 1996). It included assessment of; to assess pain specifically in premature infants. It includes assessment of; gestational age, behavioral state, heart rate, oxygen saturation, brow bulge, eye squeeze, and naso-labial furrow. The infants were scored by using indicators. Each indicator was scored on a 4-point scale (score of 0 to 3). A total score of 6 or less generally indicates minimal or no pain; a score of 7 to 12 indicates mild pain; a score greater than 12 suggests moderate to severe pain.

2- Neonatal Facial Coding System (NFCS): It was adopted from Duhn \& Medves (2004).) to assess pain in preterm neonates. The NFCS is based upon a number of different facial expressions consisting of facial brow bulge, eye squeeze, naso-labial furrow, open lips, vertical mouth stretch, horizontal mouth stretch, lip purse (the lips appear as if an "OO" sound is being pronounced), a taut tongue (characterized by a cupped tongue with sharp tensed edges), tongue protrusion, and chin quiver.Infants' scores range was from 0 (no pain) to 10 (maximum pain).

\section{Preparatory phase:}

\section{Validity and reliability}

The researchers reviewed the past, current regional and international related literatures covering all aspects of the study using textbooks, articles, journal and scientific magazines. This helped the researchers to be acquainted with the research problem and guided them in developing the study tools. To measure content validity of the study tools, the researchers assure that items of the tools were adequately represent what are supposed to measure by presented it to three experts including; one pediatric medicine, and two of pediatric nursing field from the Faculty of Nursing Cairo and El-Menofia to test the content validity. Modifications of the tools were done according to the expert's judgment as adding an observational checklist on weight improvement of neonates. And after that, the suggested changes were made then, the experts' agreed on the content.

\section{Exploratory phase:}

\section{Ethical Considerations and Human Rights:}

An official permission for data collection was obtained from administrator of Benha Specialized Hospital for children to carry out the study after submitting a letter from the researchers. A clear explanation was given about the nature, importance and expected outcomes of the study. Then participation in the study was voluntary; each nurse was informed about the purpose, procedure, benefits, and nature of the study and each nurse had the right to withdraw from the study at any time without any rationale, then oral/written consent obtained from them. As within the first week of life, parents gave informed consent to enroll their infants in the 
study. Nurses were informed that obtained data will not be included in any further researches. Confidentiality and anonymity of each subject was assured through coding of all data and all information has taken was protected.

\section{Pilot study:}

A pilot study was carried out on $10 \%$ of total sample size (6) neonates and 6 nurses over a period of one week to test the effectiveness of the study tools and the effect of applying left lateral body position on the preterm infants with GERD. And $10 \%$ of the studied nurses (6) filled out the questionnaire during investigation of the position on the pilot sample of preterm neonates. Carrying out the pilot study gave the researchers experience to deal with the included study subjects, and the data collection tools. Based on the results of the pilot study, needed modifications were done and pilot study subjects were excluded from the actual study sample.

\section{Field work}

The field work was performed from the beginning of from January 2016 to March 2016 to collect data. The researchers were available six days per week except Friday by rotation three days per week for each researcher in the morning and afternoon shifts.

\section{Procedure}

- After the pilot carried out, it was clear for all nurses that neonates who placed on LLP had improved out comes.

- The studied infants were assessed by using the study tools during NICU hospitalization.

- Ongoing education occurred as needed throughout the study. At each participant's bedside, signage was posted with positioning instructions, and a contact number was provided to call when there were challenges.

- Upon notification, the researchers would go to the bedside and demonstrate proper positioning to nursing staff.

- The numbers of nurses who were assessed and taking educational sessions per week were ranged from 4-5 nurses. The structured interviewing questionnaire sheet was filled out by the nurse and observational checklists were collected by the researchers and the average times required for completion of each tool was around 10-15 minutes. The same researcher was observing the nurses' practice regarding care of preterm infant with GERD for the same specified nurse during their actual practices.

- The studied nurses placed infants in their assigned positioning whenever lying in the incubator and when not being held or fed. If an infant needed to be removed from the assigned positioning for medical reasons or due to staff or parent compliance or error for greater than 2 hours per day, staff were recorded the time out of positioning in a bedside log.

- The researcher's team also maintained a separate record of time out of the assigned LLP position. The researchers checked that each participant was in the assigned positioning during random times at least 2 times per day to ensure that each infant was positioned correctly.

\section{Preparation phase:}

It was concerned with designing and testing different data collection tools, in addition, the administrative arrangements to carry out the study as well as to conduct the pilot study. In the beginning, the researchers introduce themselves to the nurses. prior to study initiation and over a period of one week, nursing staff who were responsible for day-to-day care of the infants were gave an oral consent to participate in the study and educated by researchers through presentations and bedside demonstrations on how to correctly position preterm infants on LLP position post prandial. Nurses who accepted to participate in the study individually interviewed by the researchers to explain the nature, purposes, and the desired outcomes of the study and an oral consent was obtained from these nurses

\section{Implementing phase:}

Data were collected from the beginning of January 2016 to March 2016. The researchers attended the selected study setting six days per week except Friday by rotation three days per week for each researcher in the morning and afternoon shifts.

Each nurse was interviewed individually for 10 15 minutes to fill out the structured interviewing questionnaire sheet (Tool 1). The researchers clarified and answered any related questions. Then, each nurse was observed during their practice on morning and afternoon shifts using nurses observational check lists by the same researcher (Tool 2). The time needed for each observation for each nurse was 20-25 minutes for three times during providing of care for preterm infants with GERD. The same researcher was observing the nurses' actual practice regarding care preterm infants with GERD for the same specified nurse during their practices. The mean of the three observations was calculated after that, and the mean score was taken.

\section{Program Construction, Implementation, and} Evaluation:

The intervention program was designed based on the actual needs assessment of nurses then implemented and evaluated. The aim of this program was to upgrade nurses' knowledge and improve their practice regarding care preterm infants with GERD. In addition, improving the 
medical outcomes of the preterm infants with GERD. The implementation of the intervention program was carried out in the previously mentioned study settings. The guiding booklet was distributed and implemented with the studied nurses whereas, the researchers explained the contents of the guiding booklet and how to use as a personal reference later on. Training of nurses was conducted using a laptop with MS Power Point presentations 2010 made from contents of the guiding booklet. The program was implemented for a group of nurses that entail (45) according to working circumstances, there mental and physical readiness.

The intervention program was implemented over four weeks period in addition to one week for pre and post-test. A time schedule suitable for nurses was developed to conduct the program that included; date, place, topic, time and duration of each session. The total number of sessions was 6 sessions for theory and practice ( 2 for theory and 4 for practice) in each setting, each session took about 30 to 35 minutes include periods of discussion during their training. In addition, 2 sessions for pre-test and post-test.

At the beginning of the first session an orientation to the program and its importance and outcomes were explained. In addition, a feedback about the previous session was done and the objectives of the new topic were explained. Simple words and Arabic language were used to suite the nurses' level of understanding. At the end of each session, nurses' questions were discussed to correct any misunderstanding. In addition to redemonstration for practical procedures.

Different teaching strategies were used for implementation of the program such as; lectures, small group discussion, brain storming, role play, demonstration and re-demonstration using real objects. Suitable teaching aids as booklet, colored posters, doll and real objects were prepared especially for practice. Nurses were motivated to cooperate and participate actively in different stages of the study

\section{Evaluation:}

Upon the completion of the intervention program the post test (evaluation) was done for the studied sample to evaluate the outcomes of the implemented program using the same tools for data collection.

\section{Administrative design}

An official permission for data collection was obtained from the hospitals' manager of Benha Specialized Hospital for children through submission of official letters issued from the dean of Benha faculty of nursing. The title, objectives, and outcomes of the study were illustrated as well as the main data items to be covered, and the study was carried out after gaining the necessary permission. The study was carried out during the period from the beginning of January 2016 to the end of March 2016.

\section{Statistical design}

To answer the research questions for this study, the collected data revised, organized, tabulated and analyzed by using SPSS (Statistical Package for the social Science Software) statistical package version 20 on IBM compatible computer. Numerical data (Quantitative data) was presented in tables by using Mean, Standard deviation $(\mathrm{X} \pm \mathrm{SD})$ and analyzed by applying $\mathrm{t}$ test for normally distributed variables, while qualitative data were expressed as frequency and percentage and chi-square was used. Additionally, other statistical tests such as Independent $t$ test. $t$ test was used as a parametric test of significance for comparison between two samples means. Pearson correlation (r) was used to measure the correlation between quantitative variables.

$\mathrm{P}$-value at .05 was used to determine significance regarding:

- P-value $>.05$ to be statistically insignificant.

- P-value $\leq 05$ to be statistically significant.

- P-value $\leq 001$ to be high statistically significant

\section{Results:}

Table (1) clarifies distribution of the studied neonates according to their characteristics. Whereas, the mean gestational age of them was $31.65 \pm 1.964$ years with a mean current age at the study time was $5.550 \pm 3.254$ days. Moreover, more than two thirds $(66.70 \%)$ of them were males. Regarding their weight on admission it was found that, the mean weight was $1716 \pm 121.517$. While their mean weight at the time of the study was1906 \pm 1319.033 .

Figure (1) illustrates that the majority (38\%\% $39 \%)$ of the studied preterm infants' gestational age was between $24<28 \& 28<32$.

Table (2) reveals the distribution of the studied nurses regarding their personal data. As more than half of them $(58.30 \%)$ have age of $20-<30$. While the majority of them $(93.30 \%)$ were females. Moreover, more than two thirds of them $(66.60 \%)$ had diploma of secondary nursing school. In addition, their mean years of experience, it was found to be $8.76 \pm 5.77$. Rather more, three quarters $(75.00 \%)$ of them had attended previous training courses related to neonatal care.

Table (3) demonstrates distribution of the studied nurses regarding their knowledge about GERD in preterm neonates. It was found that the majority of the studied nurses $(86.70 . \%, 73.30 \%, 75.00 \%$, $71.60 \%, 95.00 \%, 73.30 \%, 71.60 \%$ and $95.00 \%$ respectively) gave correct answers on post intervention test compared with pre-intervention 
test in relation to; definition, causes, signs and symptoms, types, complications, treatment and nursing management.

Figure (2) demonstrates distribution of the studied nurses regarding their total knowledge scores pre and post intervention. It was revealed that, the majority $(96 \%)$ of the studied nurses have satisfactory knowledge post intervention compared (35\%)with pre-intervention.

Table (4) views distribution of the studied nurses regarding their practice pre-and post-intervention program implementation. Whereas, there was a significant difference between nurses' practice pre and post program phases.

Figure (3) demonstrates distribution of the studied nurses regarding their total practice preand post-intervention. As found that, the majority (92\%) of the studied nurses have competent practices post intervention program implementation compared with (20\%) preintervention program implementation.

Table (5) reveals distribution of the studied preterm infants mean scores regarding medical outcomes pre-and post-intervention program implementation. It was found that the mean length of hospital stay LOS was decreased in in post program implementation to be $7.866 \pm 2.979$ compared with preprogram implementation mean LOS was $10.533 \pm 3.549$. Furthermore, the mean number of episodes of GOR was decreased in post intervention program implementation to $1.700 \pm .534$ compared with preprogram implementation as it was 4.4663 \pm .860 . Additionally, the mean duration of longest GOR in post intervention program implementation was3.066 \pm 1.257 , while in the preprogram implementation was 5.366 \pm 1.144 . Moreover, the mean vomiting episodes in preprogram implementation was $5.766 \pm 1.478$ but in the post intervention program implementation it was decreased to $5.766 \pm 1.478$. As viewed in the table, there were statistical significant differences between the program phases $(\mathrm{p}<0.001)$.

Table (6) reveals distribution of the studied preterm infants mean scores regarding their respiratory status related to GERD through the program phases. It was found that, the mean aspiration episodes related to GERD on preprogram implementation was $10.533 \pm 3.549$, while in post program implementation it was decreased to $7.866 \pm 2.979$. Regarding mean oxygen saturation level within two hours postprandial, it was noticed that in post program phase it was $87.900 \pm 2$. Moreover, number of apneas was decreased in post program phase to $1.933 \pm 1.142$ while in the preprogram implementation, it was $3.733 \pm 1.52$. There were statistical significant differences between the program phases $(\mathrm{p}<0.001)$.

Table (7) illustrates, distribution of the studied preterm infants mean scores regarding their weight gain along six days from the beginning of interventions., it was obvious an increase in weight of the studied preterm infants after the intervention program implementation compared with the preprogram implementation with a statistical significant differences $(p<0.001)$.

Table (8) presents, distribution of the studied preterm infants mean scores regarding pain scales through the program phases. It was found that, on post program implementation phase pain mean scores by the Preterm Infant Pain Profile (PIPP) was $2.1 \pm 1.4$, while, in preprogram phase the pain

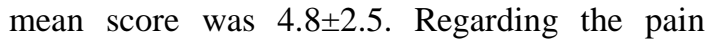
mean scores by Neonatal Facial Coding System (NFCS), it was found that on post program phase pain mean scores was $3.78 \pm 1.96$, while on preprogram phase pain mean scores was $8.03 \pm 3.01$. There were statistical significant differences between the program phases $(\mathrm{p}<0.001)$.

Table (9) reveals correlation between the studied nurses' total knowledge, total practice and medical outcomes of the studied preterm infants. As found there was a clear statistical significant correlation between nurses' total knowledge, total practice and medical outcomes post intervention.

Table (1): Distribution of the studied neonates according to their characteristics

\begin{tabular}{|l|l|l||}
\hline Neonates' characteristics & No(60) & $\%$ \\
\hline Current age at the study time & \multicolumn{2}{||}{} \\
1-<5 days & 19 & 31.70 \\
$5-<10$ day & 29 & 48.30 \\
10-<20 day & 12 & 20.00 \\
\hline X \pm ST. D & $\mathbf{5 . 5 5 0 \pm 3 . 2 5 4}$ \\
\hline Gender: & 40 & 66.70 \\
1-Male & 20 & 33.30 \\
2- Female &
\end{tabular}


Samah M. Khalaf \& Faten S. Mahmoud "Effect of Body..."

\begin{tabular}{|l|l|l||}
\hline Type of feeding & 3 & 5.00 \\
Breast feeding & 47 & 78.30 \\
Bottle feeding & 10 & 16.60 \\
Mixed type & 5 & \\
\hline Weight on admission in grams & 12 & 8.30 \\
$500<1000$ & 25 & 20 \\
$1000<1500$ & 18 & 41.70 \\
$1500<2000$ & $1716 \pm 121.517$ & 30.00 \\
$2000<2490$ & 0 & \\
\hline X \pm ST. D & 0 & 0.00 \\
\hline Weight at time of the study in gram & 90.00 \\
$<1000$ & 54 & 10.00 \\
$1000<1500$ & 6 & \\
$1500<2000$ & & \\
$2000<2500$ & \multicolumn{2}{|l||}{} \\
\hline$X \pm$ ST. D 1810 \pm 90.44 &
\end{tabular}

Figure(1):Gestational age of the studied neonates

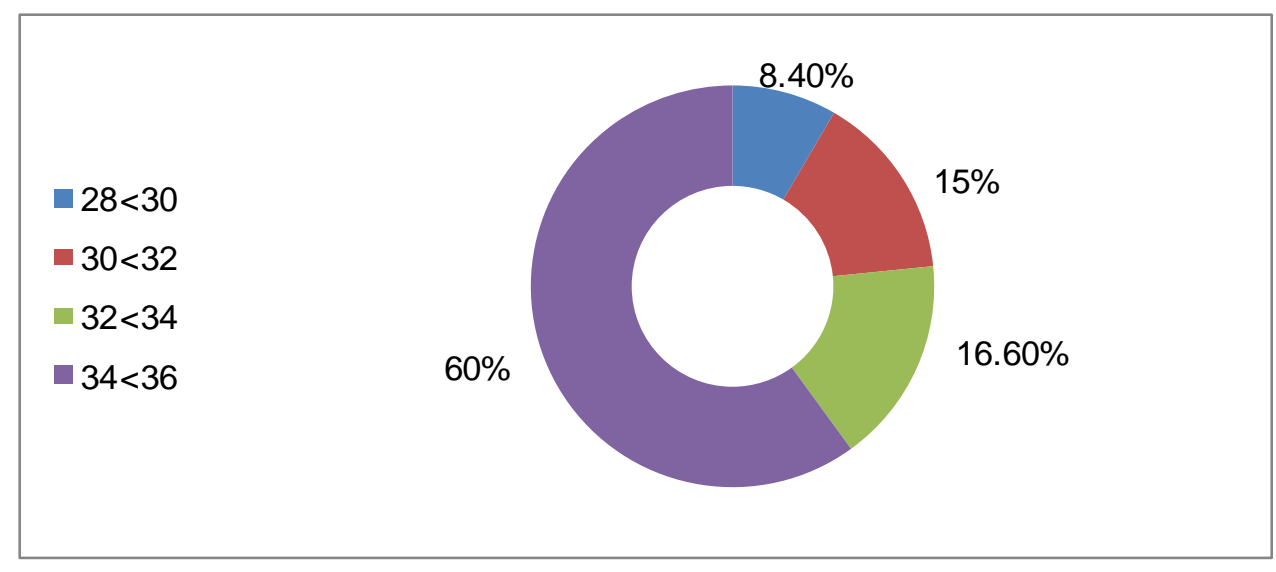

Table (2):Distribution of the studied nurses regarding their personal data

\begin{tabular}{|c|c|c|}
\hline Personal characteristics & No(60) & $\%$ \\
\hline \multicolumn{3}{|l|}{ Age in years } \\
\hline$-20-<30$ & 35 & 58.30 \\
\hline$-30-<40$ & 15 & 25.00 \\
\hline$-\geq 40$ & 10 & 16.60 \\
\hline $\mathrm{X} \pm \mathrm{SD}$ & \pm 6.561 & \\
\hline \multicolumn{3}{|l|}{ Gender: } \\
\hline - Male & 4 & 6.66 \\
\hline - Female & 56 & 93.30 \\
\hline \multicolumn{3}{|l|}{ Educational level } \\
\hline - Diploma of secondary nursing school & 40 & 66.60 \\
\hline - Diploma of Technical Institute of nursing & 14 & 23.30 \\
\hline - Bachelor degree in nursing & 6 & 10.00 \\
\hline \multicolumn{3}{|l|}{ Years of experience at NICU } \\
\hline $1-<10$ years & 47 & 78.30 \\
\hline$\geq 10$ years & 13 & 21.60 \\
\hline $\begin{array}{ll}\mathrm{X} \pm \mathrm{SD} & 8.7\end{array}$ & \pm 5.77 & \\
\hline \multicolumn{3}{|c|}{ Attendance of previous training courses related to neonatal care } \\
\hline yes & 45 & 75.00 \\
\hline No & 15 & 25.00 \\
\hline
\end{tabular}


Samah M. Khalaf \& Faten S. Mahmoud "Effect of Body..."

Table (3): Distribution of the studied nurses regarding their knowledge about GERD in preterm neonates.

\begin{tabular}{|c|c|c|c|c|c|c|}
\hline \multirow[t]{2}{*}{$\begin{array}{l}\text { Nurses' } \\
\text { knowledge }\end{array}$} & \multicolumn{2}{|c|}{$\begin{array}{l}\text { Pre } \\
\text { implementation }(60)\end{array}$} & \multicolumn{2}{|c|}{$\begin{array}{l}\text { Post program } \\
\text { implementation } \\
(60)\end{array}$} & \multirow[t]{2}{*}{$\mathbf{X}^{2}$} & \multirow[t]{2}{*}{ P value } \\
\hline & No & $\%$ & No & $\%$ & & \\
\hline \multicolumn{5}{|l|}{ Definition } & \multirow{3}{*}{52.85} & \multirow{3}{*}{$0.000^{* *}$} \\
\hline - Correct & 8 & 13.30 & 48 & 80.00 & & \\
\hline - Incorrect & 52 & 86.70. & 12 & 20.00 & & \\
\hline \multicolumn{6}{|l|}{ Causes } & \\
\hline - Correct & 22 & 35.70 & 54 & 90.00 & \multirow[t]{2}{*}{11.16} & \multirow[t]{2}{*}{$0.000^{* *}$} \\
\hline - Incorrect & 38 & 63.30 & 6 & 10.00 & & \\
\hline \multicolumn{6}{|c|}{ Signs and symptoms } & \\
\hline - Correct & 19 & 31.60 & 45 & 75.00 & \multirow[t]{2}{*}{43.03} & \\
\hline - Incorrect & 41 & 68.30 & 15 & 25.00 & & $0.000^{* *}$ \\
\hline \multicolumn{6}{|l|}{ Types } & \\
\hline - Correct & 12 & 20.00 & 57 & 95.00 & \multirow[t]{2}{*}{32.45} & \\
\hline - Incorrect & 48 & 80.00 & 3 & 5.00 & & $0.000^{* *}$ \\
\hline \multicolumn{6}{|c|}{ Complications } & \\
\hline - Correct & 8 & 13.30 & 44 & 73.30 & \multirow[t]{2}{*}{42.93} & $0.000^{* *}$ \\
\hline - Incorrect & 52 & 86.70 & 16 & 26.60 & & \\
\hline \multicolumn{6}{|l|}{ Treatment } & \\
\hline - Correct & 12 & 20.00 & 43 & 71.60 & \multirow[t]{2}{*}{10.06} & $0.000^{* *}$ \\
\hline - Incorrect & 48 & 80.00 & 17 & 28.30 & & \\
\hline \multicolumn{6}{|c|}{ Nursing management } & \\
\hline - Correct & 16 & 26.60 & 57 & 95.00 & \multirow[t]{2}{*}{9.06} & \multirow[t]{2}{*}{$0.000^{\text {** }}$} \\
\hline - incorrect & 44 & 73.30 & 3 & 5.00 & & \\
\hline
\end{tabular}

NS $\mathrm{p}>0.05$

$\mathrm{p}^{*<0.05} \mathrm{p}<0.001 * *$

Table (4): Distribution of the studied nurses regarding their practice in caring for neonates with GERD pre and post program.

\begin{tabular}{|c|c|c|c|c|c|c|}
\hline \multirow[t]{2}{*}{ Nurses' practice } & \multicolumn{2}{|c|}{$\begin{array}{lc}\text { Pre } & \text { program } \\
\text { implementation }(60)\end{array}$} & \multicolumn{2}{|c|}{$\begin{array}{l}\text { Post program } \\
\text { implementation }(60)\end{array}$} & \multirow[t]{2}{*}{$\mathbf{X}^{2}$} & \multirow[t]{2}{*}{ P value } \\
\hline & No & $\%$ & No & $\%$ & & \\
\hline \multicolumn{5}{|c|}{$\begin{array}{l}\text { Place the preterm on the left lateral position for } 30 \text { minutes post } \\
\text { prandial }\end{array}$} & \multirow[t]{3}{*}{-} & \multirow[t]{3}{*}{-} \\
\hline - done & 0 & 0.00 & 60 & 100.00 & & \\
\hline - not done & 60 & 100 & 0.00 & 0.00 & & \\
\hline \multicolumn{7}{|c|}{ Record number of GOR } \\
\hline - done & 12 & 20.00 & 54 & 90.00 & \multirow[t]{2}{*}{10.16} & \multirow[t]{2}{*}{$0.000^{* *}$} \\
\hline - notdone & 48 & 80.00 & 6 & 10.00 & & \\
\hline \multicolumn{7}{|c|}{ Monitor O2 saturation level within two hours postprandial } \\
\hline - done & 9 & & 55 & 91.60 & \multirow[t]{2}{*}{43.03} & \multirow[t]{2}{*}{$<0.001^{* * *}$} \\
\hline - notdone & 51 & & 5 & 8.30 & & \\
\hline \multicolumn{7}{|c|}{ Record number of the longest GOR } \\
\hline - done & 0 & 0.00 & 43 & 71.60 & \multirow[t]{2}{*}{-} & \multirow[t]{2}{*}{-} \\
\hline - not done & 60 & 100 & 17 & 28.30 & & \\
\hline \multicolumn{7}{|c|}{$\begin{array}{l}\text { Record number of minutes until clearance of any GOR episode over a 24-hour } \\
\text { period }\end{array}$} \\
\hline - done & 0 & 0.00 & 57 & 95.00 & \multirow[t]{2}{*}{-} & \multirow[t]{2}{*}{-} \\
\hline - not done & 60 & 100.00 & 3 & 5.00 & & \\
\hline \multicolumn{7}{|c|}{ Record number of apneas } \\
\hline - done & 8 & 13.30 & 54 & 73.30 & \multirow[t]{2}{*}{42.93} & \multirow[t]{2}{*}{$<0.001^{* * 2}$} \\
\hline - notdone & 52 & 86.70 & 6 & 26.60 & & \\
\hline \multicolumn{7}{|c|}{ Weighing of preterm daily } \\
\hline - done & 22 & 36.60 & 43 & 71.60 & \multirow[t]{2}{*}{10.06} & \multirow[t]{2}{*}{$<0.001^{* * *}$} \\
\hline - notdone & 38 & 63.30 & 17 & 28.30 & & \\
\hline
\end{tabular}


Samah M. Khalaf \& Faten S. Mahmoud "Effect of Body..."

\begin{tabular}{|c|c|c|c|c|c|c|}
\hline \multicolumn{6}{|c|}{ Assessing pain intensity } & \multirow{3}{*}{$<0.001^{* *}$} \\
\hline - done & 16 & 26.60 & 57 & 95.00 & \multirow[t]{2}{*}{9.06} & \\
\hline - not done & 44 & 73.30 & 3 & 5.00 & & \\
\hline \multicolumn{7}{|c|}{-Use non pharmachological pain relief } \\
\hline - done & 6 & 10.00 & 58 & 96.60 & \multirow{2}{*}{41.02} & \multirow{2}{*}{$<0.001^{* *}$} \\
\hline - notdone & 54 & 90.00 & 2 & 3.30 & & \\
\hline \multicolumn{7}{|c|}{ Educate parents at discharge and follow up care } \\
\hline - done & 0 & 0.00 & 60 & 100 & & \multirow{2}{*}{ - } \\
\hline - notdone & 60 & 100 & 0 & 0.00 & & \\
\hline
\end{tabular}

NS $p>0.05 \quad p^{*<0.05} \quad \mathrm{p}<0.001 * *$

Figure (2): Distribution of the studied nurses regarding their total knowledge scores pre and post intervention program.

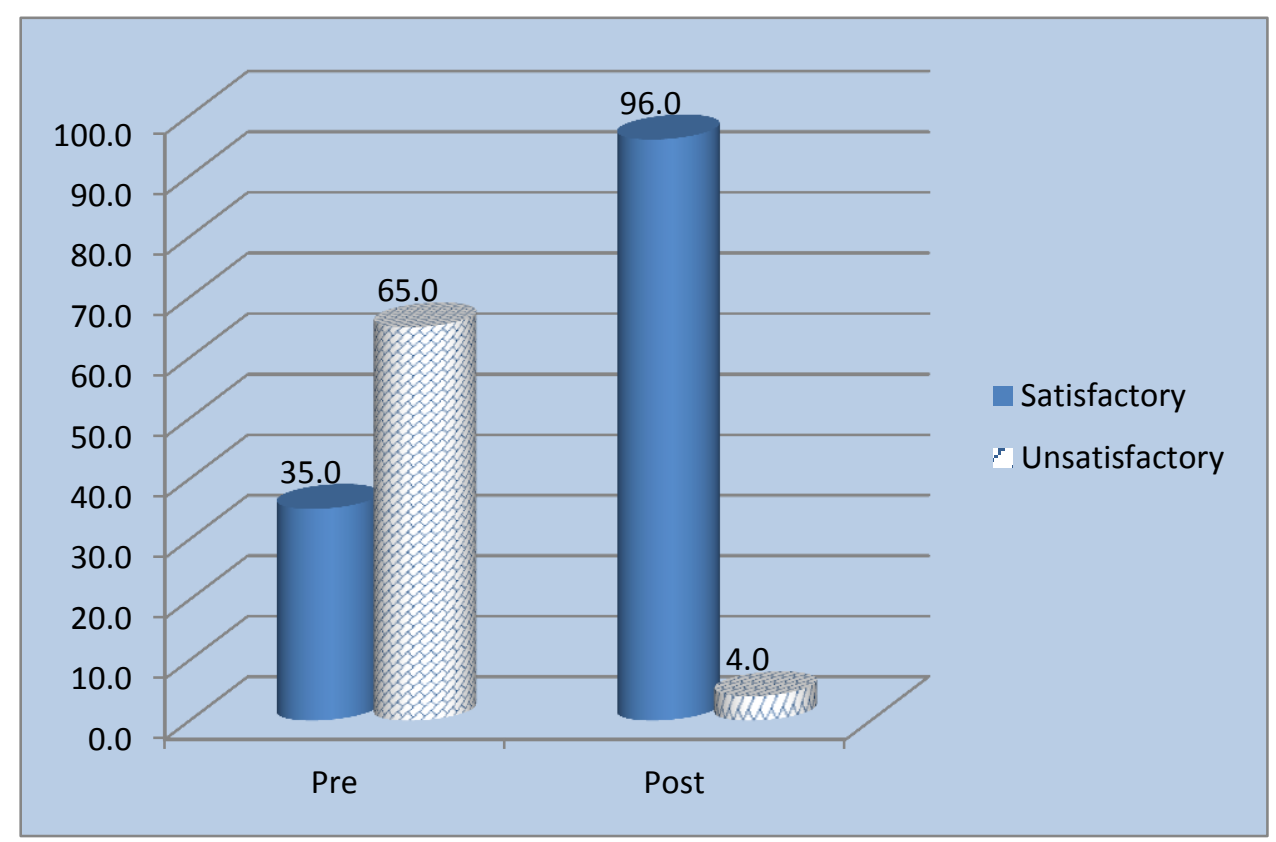

Figure(3): Distribution of the studied nurses regarding their total practice scores pre and post intervention program

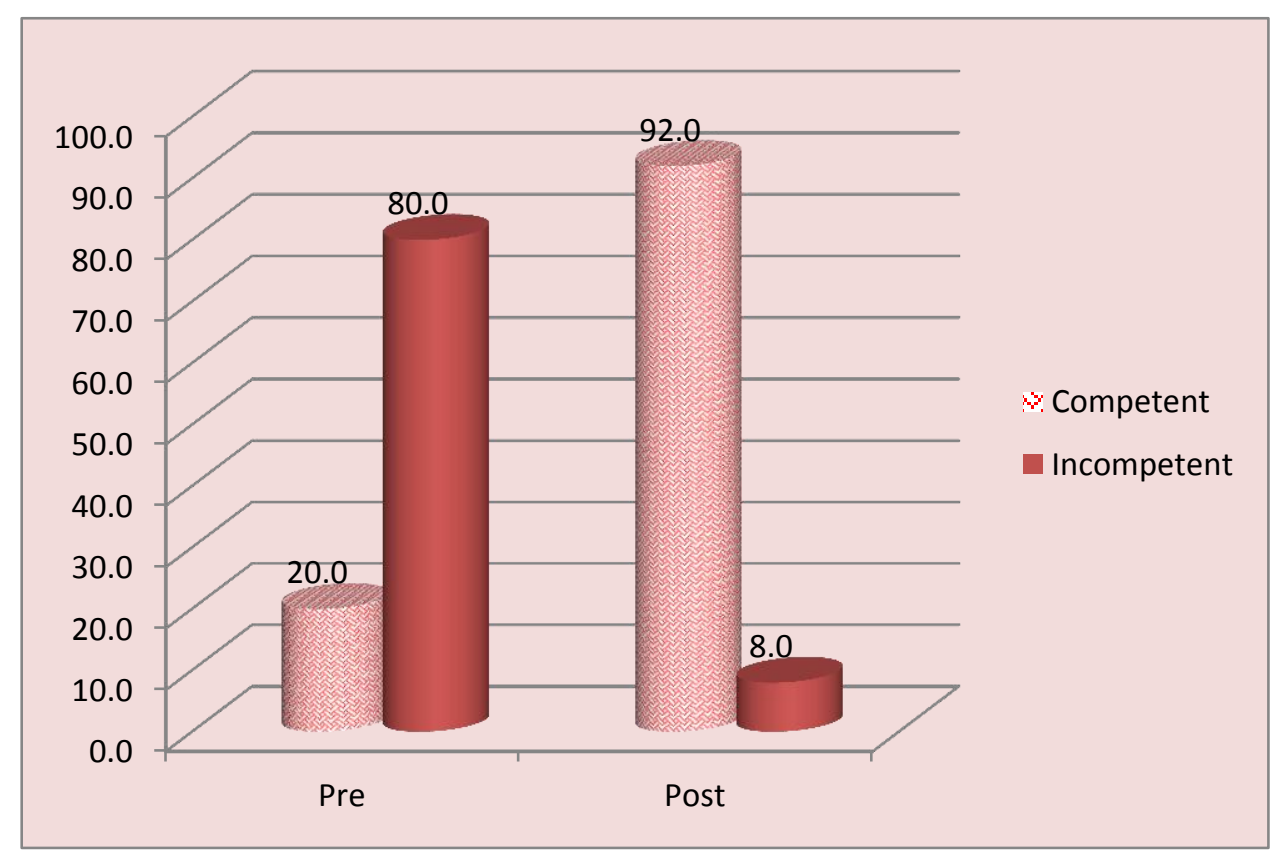


Samah M. Khalaf \& Faten S. Mahmoud "Effect of Body..."

Table (5): Distribution of the studied preterm infants mean scores regarding medical outcomes through the program phases

\begin{tabular}{|l|l|l|l|l|}
\hline \multirow{2}{*}{ Medical outcomes } & \multicolumn{2}{|c|}{ The studied neonates (n=60) } & \multicolumn{2}{|c|}{ p } \\
\cline { 2 - 4 } & $\begin{array}{c}\text { Pre program } \\
\text { implementation }\end{array}$ & $\begin{array}{c}\text { Post program } \\
\text { implementation }\end{array}$ & \multirow{2}{*}{ t } & \\
\cline { 2 - 5 } & \multicolumn{1}{|c|}{ Mean \pm ST. D } & \multicolumn{1}{|c|}{ Mean \pm ST. D } & & \\
\hline Length of hospital stay (LOS) & $10.533 \pm 3.549$ & $7.866 \pm 2.979$ & 6.93 & $<0.001^{* *}$ \\
\hline $\begin{array}{l}\text { Number of episodes of GORS over a } \\
\text { 24h }\end{array}$ & $4.4663 \pm .860$ & $1.700 \pm .534$ & 16.20 & $<0.001^{* *}$ \\
\hline $\begin{array}{l}\text { Number of minutes until clearance of } \\
\text { any GOR episode over a 24-hour period }\end{array}$ & $4.800 \pm .3 .188$ & $2.033 \pm .1 .040$ & 5.54 & $<0.001^{* *}$ \\
\hline Duration of longest GOR & $5.366 \pm 1.144$ & $3.066 \pm 1.257$ & 4.03 & $<0.001^{* *}$ \\
\hline $\begin{array}{l}\text { Vomiting episodes (total number over a } \\
\text { 24-hour period). }\end{array}$ & $5.766 \pm 1.478$ & $2.586 \pm 0.894$ & 11.06 & $<0.001^{* *}$ \\
\hline
\end{tabular}

NS $p>0.05 \quad p^{*}<0.05 p<0.001 * *$

Table (6): Distribution of the studied preterm infants mean scores regarding their respiratory status related to GERD through the program phases.

\begin{tabular}{|l|l|l|l|l||}
\hline \multirow{2}{*}{ Respiratory status } & \multicolumn{3}{|c|}{ The studied preterm infants (n=60) } \\
\cline { 2 - 5 } & \multicolumn{1}{|c|}{$\begin{array}{c}\text { Pre program } \\
\text { implementation }\end{array}$} & $\begin{array}{c}\text { Post program } \\
\text { implementation }\end{array}$ & \multirow{2}{*}{ t } \\
\cline { 2 - 5 } & Mean \pm ST. D & Mean \pm ST. D & \\
\hline Aspiration episodes related to GERD & $10.533 \pm 3.549$ & $7.866 \pm 2.979$ & 6.934 & $<0.001 * *$ \\
\hline $\begin{array}{l}\text { Oxygen saturation within two hours } \\
\text { postprandial. }\end{array}$ & $87.900 \pm 2.155$ & $92.33 \pm 1.516$ & 7.68 & $<0.001 * *$ \\
\hline Apnea (number over a 24-hour period & $3.733 \pm 1.52$ & $1.933 \pm 1.142$ & 5.634 & $<0.001 * *$ \\
\hline
\end{tabular}

NS $\mathrm{p}>0.05 \quad \mathrm{p}^{*<0.05} \mathrm{p}<0.001 * *$

Table(7): Distribution of the studied preterm infants mean scores regarding their weight gain along six days from the beginning of interventions the program phases.

\begin{tabular}{||l|l|l|l|c||}
\hline \multirow{3}{*}{ Weight Gain } & \multicolumn{4}{|c|}{ The studied neonates (n=60) } \\
\cline { 2 - 5 } & \multicolumn{1}{|c|}{$\begin{array}{c}\text { Pre program } \\
\text { implementation }\end{array}$} & $\begin{array}{c}\text { Post program } \\
\text { implementation }\end{array}$ & $\mathrm{t}$ & $\mathrm{p}$ \\
\cline { 2 - 5 } & Mean \pm ST. D & Mean \pm ST. D & \\
\hline First day & $\mathbf{1 8 0 5} \pm \mathbf{9 1 . 8 5}$ & $\mathbf{1 8 1 0} \pm \mathbf{8 5 . 6 1 7}$ & $\mathbf{. 5 3 4}$ & $<\mathbf{0 . 0 5}$ \\
\hline Second day & $\mathbf{1 8 1 2} \pm \mathbf{9 4 . 6 7}$ & $\mathbf{1 8 2 4} \pm \mathbf{1 1 0 . 4 0 5}$ & $\mathbf{0 . 8 0}$ & $<\mathbf{0 . 0 5}$ \\
\hline Third day & $\mathbf{1 8 1 8} \pm \mathbf{9 0 . 5 6 5}$ & $\mathbf{1 8 4 6} \pm 107.23$ & $\mathbf{1 . 0 1 1}$ & $<\mathbf{0 . 0 5}$ \\
\hline Fourth day & $\mathbf{1 8 2 3} \pm \mathbf{9 2 . 4 7}$ & $\mathbf{1 8 6 7} \pm \mathbf{1 1 4 . 0 3}$ & $\mathbf{1 . 0 3 9}$ & $<\mathbf{0 . 0 5}$ \\
\hline Fifth day & $\mathbf{1 8 2 7} \pm \mathbf{9 5 . 9 8}$ & $\mathbf{1 8 8 9} \pm 116.63$ & $\mathbf{. 9 4 0}$ & $<\mathbf{0 . 0 5}$ \\
\hline Sixth day & $\mathbf{1 8 4 2} \pm \mathbf{9 5 . 9 7}$ & $\mathbf{1 8 9 9} \pm \mathbf{1 1 6 . 4 9}$ & $\mathbf{. 9 1 8}$ & $<\mathbf{0 . 0 5}$ \\
\hline
\end{tabular}

NS $\mathrm{p}>0.05 \mathrm{p}^{*<0.05} \mathrm{p}<0.001^{* *}$

Table (8): Distribution of the studied preterm infants mean scores regarding pain scales through the program phases. 
Samah M. Khalaf \& Faten S. Mahmoud "Effect of Body..."

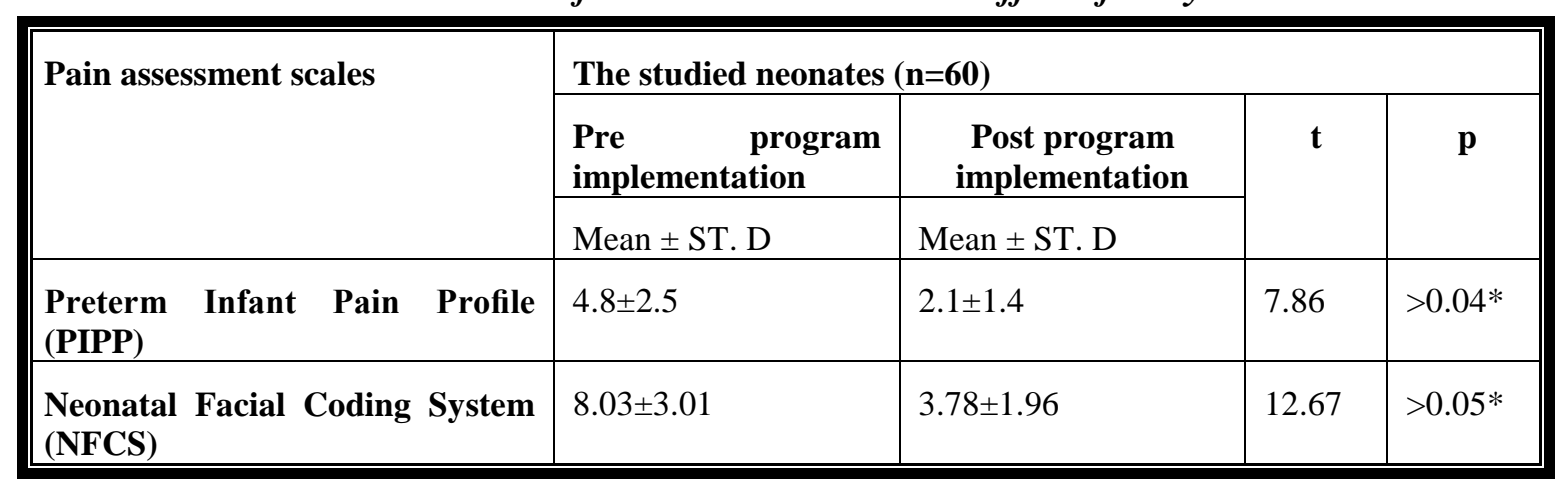

NS $p>0.05 \quad p^{*}<0.05 \quad p<0.001 * *$

Table(9): Correlation between the studied nurses' total knowledge, practice and medical outcomes of the studied preterm infants post intervention program implementation.

\begin{tabular}{|c|c|c|c|c|c|c|}
\hline \multirow[t]{2}{*}{ Items } & \multicolumn{2}{|c|}{$\begin{array}{c}\text { Total } \\
\text { knowledge }\end{array}$} & \multicolumn{2}{|c|}{ Total practice } & \multicolumn{2}{|c|}{ Medical outcomes } \\
\hline & $\mathbf{r}$ & $\mathbf{p}$ & $\mathbf{R}$ & $\mathbf{p}$ & $\mathbf{r}$ & p \\
\hline - Total knowledge & 1 & - & .98 & .000 & .65 & .000 \\
\hline - $\quad$ Total practice & 0.46 & .000 & 1 & - & .78 & .000 \\
\hline - Medical outcomes & .37 & .000 & .49 & .000 & 1 & - \\
\hline
\end{tabular}

NS p $>0.05 \quad p^{*}<0.05 \quad \mathrm{p}<0.001 * *$

\section{Discussion:}

Premature infants are at risk for many long term health problems. One that can be very distressing to parents and caregivers is prolonged and recurrent gastroesophageal reflux (GOR), which may be accompanied with other symptomatic disorders as; regurgitation, crying, irritability and arching thus develop a condition called (GERD). Infants who are afflicted with GERD experience the symptoms within 30 minutes of feeding. Conflicting data or lack of data affects effective interventions and can be confusing or misleading to caregivers (Valeriu et al., 2015).

Generally, gastro-esophageal reflux disease (GERD) is a common condition among preterm infants, due to several physiological promoting factors. To limit the potentially harmful widespread of pharmacological treatment, a step-wise approach, which firstly applies conservative strategies, is currently considered the best choice to manage GERD in the preterm infants. Among the most common conservative strategies, postural measures seem to represent an effective measure to reduce GERD features help in nursing management of those symptomatic preterm infants. So, the aim of the current study was to evaluate the effect of body positioning intervention program on reliving gastroesophageal reflux disease in preterm infants.

Concerning characteristics of the studied neonates, it was found that more than two thirds of them were males. This is in accordance with Corrvalia et al., ( 2009) who found that more than half of preterm neonates with GERD were males. But controversially regarding the mean gestational age were 29 weeks with a mean birth weight of $1274 \mathrm{~g}$ were enrolled in the study at a mean age of 38 days with a mean weight of $1733 \mathrm{~g}$ as compared with the current study results whereas, mean gestational age of the them was $31.65 \pm 1.964$ weeks with mean weight on admission $1716 \pm 121.517$.

Regarding personal characteristics of the studied nurses. It was found that, more than half of them have age of $20<30$ years. While the majority of them were females and, more than two thirds of them had diploma of secondary nursing school.This could be attributed to, the greater fraction of the nurses in Egypt was females. Moreover, more than two thirds of them had diploma of secondary nursing school. This may be due to preferences of the highest percentage of them not to complete higher nursing education. In addition their mean years of experience, was $8.76 \pm 5.77$. Rather more, three quarters of them had attended previous training courses related to neonatal care. This could be attributed to increase awareness of hospital administration by the importance of conducting regular training program for nurses at neonatal intensive care units.

Regarding total practice scores of the studied nurses. there was a highly statistical significant improvement for nurses who achieve competent scores regarding care of preterm neonates with GERD post intervention program implementation. As mentioned by Darcy, (2009) that, preterm infants, like all other newborns, should have a qualified healthcare provider assigned to their care during the postpartum recovery period following 
birth. Because they require increased surveillance and monitoring.

Regarding the effect of the intervention program on the studied nurses' knowledge and practice it was noticed an improvement on post intervention program total knowledge and practice scores. This is in accordance with Montanholi et al., (2011) who stated that, teaching and training are essential for the nursing staff members to improve the quality of healthcare and to acquire new knowledge and skills. Educational programs are considered as means for providing nurses with theoretical and technical information needed to acquire new skills and to continually improve nursing practice. Also, it helps them to accept responsibilities for their professional development.

Concerning correlation between the studied nurses' total knowledge, total practice and medical outcomes. It was found that, there was a clear statistical significant correlation between nurses' total knowledge, total practice and medical outcomes post intervention. This might be due to the improvement in knowledge reflects improvement in practice. This as reported by Pfister, (2011) that, several neonatal nursing texts recommend interventions for neonatal GERD such as; elevating the head of the bed, holding the infant upright after feeds, and prone positioning with the head of the bed elevated, without sufficient supporting evidence. As, many caregivers in neonatal intensive care units(NICUs) position infants with the head of the bed elevated, an anecdotal remedy, upon the recommendations of outdated reference books that offer conflicting advice, or they place the infant in a prone position despite the recommendation of the American Academy of Pediatrics against the practice after 37 weeks.

In relation to distribution of the studied preterm infants regarding their respiratory status related to GERD. It was found, that, number of apneas was decreased in the post program intervention compared with preprogram implementation. As, Corvaglia et al., (2009) who found that there was a variable rate of apneas can be triggered by GER in very preterm infants. So, further studies are needed to recognize clinical features to identify those. Moreover, Pfister, (2011) stated that, preterm infants who experience symptoms from GER may also experience apneic episodes and may be diagnosed with apnea of prematurity. Clinicians and caregivers often see an association with the two conditions.

Regarding the effect of the intervention training on the medical outcomes of the preterm neonates. It was found that, the mean length of hospital stay (LOS) was decreased in the post program phase compared with the mean LOS on preprogram phase. Furthermore, the mean number of episodes of GOR was decreased in the post program phase compared with the preprogram phase. Additionally, the mean duration of longest GOR in the post program phase was less than in the preprogram phase.Moreover, the mean vomiting episodes in the preprogram phase was higher than on the post program phase with statistical significant differences between the program phases. This could be contributed to that, when infants are placed in the left-sided position, the stomach contents pool in the body and greater curvature of the stomach and do not travel toward the lower esophageal sphincter easily. This is supported by Hardy, (2012) who found that, infants showed fewer episodes of nonacid GER when placed in the prone and left-side lying positions. The infants also had fewer episodes of acid GER. Moreover, left-side lying positions, and prone position demonstrating the least occurrences of GER.

In examining pain accompanied GOR episodes in the studied preterm infants, it was found that, the post program pain mean scores by the Preterm Infant Pain Profile (PIPP) was decreased compared with post program implementation pain mean scores still high. Also, regarding their pain mean scores by Neonatal Facial Coding System (NFCS), on the post program implementation pain mean scores were less than the preprogram pain mean scores. It was noticed, statistical significant differences between the program phases $(\mathrm{p}<0.001)$. This may be due to, during GOR episodes preterm infants experience heart burn and discomfort which induce sensory stimulation in the form of pain. As, reported by Khan \& Orenstein, (2010) that, severe reflux may predispose to feeding refusal, and, in turn, to inadequate caloric intake, due to pain provoked by esophageal acid exposure during meals. In addition, loss of nutrients and calories due to emesis may predispose infant to poor growth.

As regard to the mean and standard deviations of the studied preterm infants' weight gain along six days from the beginning of interventions. It was obvious an increase in weight on post intervention program implementation compared with preprogram implementation with a statistical significant difference. This may be due to that, the intervention helped in decreasing number of vomiting episodes and the amount of loss was decreased. So, the preterm infant able to gain weight. This is supported by Kimball \& Carlton, (2011) who stated that, failure to thrive or poor weight gain can be the result of recurrent regurgitation and is a warning sign of GERD that should alter the clinical approach and management. Poor weight gain despite an adequate intake of calories should prompt an evaluation for causes of regurgitation and weight loss due to GERD.

Regarding the effect of the intervention program by positioning the preterm infants with GERD on left lateral position it was found an improvement in weight, and medical outcomes of those infants with relieving of accompanied problems. This supported by Schurr\& Findlater (2012) who reported that, 
Samah M. Khalaf \& Faten S. Mahmoud "Effect of Body..."

infant positioning in the prone and left side-lying position seems to be a simple intervention for providing some albeit variable benefit in infant's suffering for symptoms of GER. However, the importance of infant positioning in the role of SIDS prevention should not be forgotten. In the monitored conditions of the NICU, anti reflux positions may be implemented but post discharge families should revert to supine positioning as recommended for SIDS prevention. Family education is paramount in emphasizing proper positioning post discharge.

In the same context, Corvaglia et al., (2007) stated that infant's anatomy may contribute to a high incidence of reflux. As in a supine position coupled with a high liquid diet, the gastroesophageal junction is continually submerged in fluid. So, when placed in a left side-lying or prone position, that juncture is clear of fluid. These positions were found to decrease the incidence of GER. In spite of the fear of SIDS accompanied with prone position in infants $>37$ weeks after discharge.

In the same line, Hassall, (2008) Who stated that, non-pharmacologic approaches are first-line therapy and can be taught to parents at a primary care level to decrease unnecessary drug treatment. Additionally, Hardy, (2012) recommended developing a protocol of care involving left sided positioning of the preterm infant which could decrease the number of GER events. As, those infants are more likely to experience fewer events of GER. Since GER is often an antecedent to apnea, brady cardia, and desaturations. Moreover, using this position has also, the potential to lead a decrease in the number of these experiences in this vulnerable population. In addition, the frequency and volume of emesis will potentially decrease along with the incidence of aspiration following emesis.

Last with respect to the theoretical framework, this research supports the intervention program for nurses regarding the application of supportive techniques of body positioning by placing preterm infants on left lateral position post prandial for 30 minutes with nursing intervention thus help in relieving GERD and its associated problems in a high degree. This supported by Hammell, (2009) that the left lateral body position is beneficial in reducing episodes of GERD in preterm infants. In addition, left lateral positioning is an inexpensive, non-pharmacological approach that can be easily taught to parents and caregivers as a first step to remedying GERD.

\section{Conclusion:}

Based on the results of the current study, it can be concluded that, the intervention program is highly effective and successful method in upgrading nurses' knowledge, and enhancing their practice regarding care of preterm infants with GERD. Rathermore preterm infants who exposed to the intervention program in the form of body positioning had better mean scores in relation to their medical outcomes post program compared with preprogram intervention

\section{Recommendations:}

The recommendations for further research in this population are many:

1. Program intervention in the form of body positioning should be integrated as apart of routine daily care of preterm infants with gastroesophageal reflux disease.

2. There is a need for studies in which a more diverse group of infants are studied, both culturally and geographically.

3. Additional research should be completed comparing each of the body positions against each other in relieving GERD.

4. Left lateral position should be proved and applied in relieving GOR in preterm neonates during hospitalization in NICU and after discharge.

5. The current nursing textbooks and handbooks need to be updated and each unit's policy and standards of care need evidence based resources with current recommendations from current research.

\section{Limitation of the study:}

There was a main limitation encountered in the course of this study which must be acknowledged. That the sample size used in this study was a small purposive sample $(n=60)$ limits the generalizability of the results of this study to a larger population.

\section{Acknowledgements:}

Deepest thanks to hospital administration for their permission, cooperation, and kindly help during the practical part of the work. We express our gratitude and thanks towards all the participated nurses who have directly helped us to complete this study and their support in each step of the study. Also, a greatest thanks for parents of the studied preterm infants for their acceptance to involve their infants in the current study.

\section{References:}

[1] Chairs C., Vandenplas, Y.,\& Rudolph, C., D.(2009). Pediatric Gastroesophageal Reflux Clinical Practice Guidelines: Joint Recommendations of the North American Society for Pediatric Gastroenterology, Hepatology, and Nutrition (NASPGHAN) and the European Society for Pediatric Gastroenterology, Hepatology, and Nutrition (ESPGHAN). Journal of Pediatric Gastroenterology \& Nutrition. 49(4)pp:498-574.

[2] Corvaglia L, Rotatori R, Ferlini M, Aceti A, Ancora G,\& Faldella G. (2007).The effect of body positioning on gastroesophageal reflux in 
premature infants: evaluation by combined impedance and $\mathrm{pH}$ monitoring. J Pediatr.;151(6)pp:591-596.

[3] Corvaglia L, Zama D, Gualdi S, Ferlini M, Aceti A, \&Faldella G. (2009): Gastro-oesophageal reflux increases the number of apneas in very preterm infants. Arch Dis Child Fetal Neonatal Ed. 94(3)pp:188-211.

[4] Corvaglia L.,Legnani E.,\&Galletti S.(2012):Lack of efficacy of a starch-thickened preterm formula on gastro-oesophageal reflux in preterm infants: a pilot study.The journal of maternal fetal neonatal medicine.12 (25): 2735-2738.

[5] Darcy, A.E.(2009): Complications of the late preterm infant. J Perinat Neonatal Nurs.23:7886.

[6] Duhn, L. J., \& Medves, J. M. (2004). A systematic integrative review of infant pain assessment tools. Advances inNeonatal Care. 4(3): 126-140.

[7] Hammell, G. L.(2009).Critical Review: The effects of left lateral body positioning on GERD, during feeding and post-feeding of the preterm infant

[8] Hassall, E.( 2008). Talk is cheap, often effective: symptoms in infants often respond to nonpharmacologic measures. Pediatr. J;152:301310.

[9] Hardy, H.(2012). Reducing Gastroesophageal Reflux in Preterm Infants. Advances in Neonatal Care. 10 (3) p. 157.

[10] KhanS., and Orenstein S. R.(2010). Gastroesophageal Reflux Disease in infants and children. Division of Pediatric Gastroenterology, University of Pittsburgh School of Medicine, Children's Hospital of Pittsburgh, chapter 4, pp:46-64.

[11] Lightdale JR,\& Gremse DA.( 2013).Section on Gastroenterology Hepatology, and Nutrition. Gastroesophageal reflux: management guidance for the pediatrician. Pediatrics.;131:e1684-95.

[12] Kimball AL,\& Carlton DP.( 2011).Gastroesophageal reflux medications in the treatment of apnea in premature infants. $\mathbf{J}$ Pediatr.;138:355-360.

[13] Maroney D.I, (2015) Gastroesophageal Reflux in Premature Infants. 1153, (301)601-9541. Retrived from http://www.reflux.org.

[14] Martin R.(2016): Gastroesophageal reflux in premature infantsLiterature review.Retrived from http://wwwnew -medical.net / health Gastresophageal disease

[15] Montanholi L. L., Merighi. M.B., \& de Jesus M.(2011).The role of the nurse in the neonatal intensive care unit: between the ideal, the real and the possible. Rev. Latino-Am. Enfermagem. 19 (2)pp:12-15.

[16] Nestle Nutrition Institute work shop Series.(2015). Global Incidence of Preterm Birth. 81:9-15.
[17] Pfister, S. (2011). A Critical Review of the Literature Regarding Positioning for the Treatment of Gastroesophageal Reflux in Neonates. Retrived from http://wwwnew medical.net / health /Gastresophageal disease

[18] Schurr, P. \& Findlater, C.(2012). Neonatal Mythbusters: Evaluating the Evidence For and Against Pharmacologic and Non pharmacologic Management of Gastroesophageal Relux Springer Publishing Company. 31( 4):229-241.

[19] Valeriu V. Lupu, Ancuta, I., Gabriela P.,\& Marin B.(2015). Gastrroesophageal reflux in newborn and infants.Romanian Journal of Pediatrics 10 ( 4)pp: 36-79.

[20] Vandenplas Y, Rudolph CD, \& DiLorenzo C. (2009). Pediatric gastroesophageal reflux clinical practice guidelines: Joint recommendations of the North. American Society for Pediatric Gastroenterology, Hepatology, and Nutrition (NASPGHAN) and the European Society for Pediatric Gastroenterology Hepatology and Nutrition(ESPGHAN) J Pediatr Gastroenterol Nutr .49:498

[21] Sangers, H., de Jong,P.M,Mulder, G.D., Stigter, C.M., Te Pas, F.J.\& Walther, F.J.(2013).Outcomes of gastric residuals whilst feeding preterm infants in various body positions. Division of Neonatology, WillemAlexander Children's Hospital, Leiden UniversityMedical Center, Journal of Neonatal Nursing. 19:337-341.

[22] Steven J. C., \&Blanchard Z. A.(2013). Gastroesophageal Reflux Disease in Neonates and Infants. When and How to Treat?

[23] Stevens, B., Johnston, C., Petryshen, P., \& Taddio, A. (1996).Premature infant pain profile: development and initialvalidation. Clinical Journal of Pain, 12(1)pp:13-22.

[24] Sudarshan R. Jadcherla, MD, Jonathan L. Slaughter, Michael R. Stenger, MD,Mark Klebanoff, Kelly Kelleher, MD, MPH,\& Gardner,W. (2013).Practice Variance, Prevalence, and Economic Burden of Premature Infants Diagnosed. by the American Academy of Pediatrics.pp:335341.www.hospitalpediatrics.org

[25] The Right Diagnosis (2016). Statistics by Country for Premature Birth.Retrived at www.right diagnosis.com 